
\title{
28 Research Square \\ Blood gas tension and acidity level of caries exposed vital pulps in primary molars
}

\section{Aviv Shmueli}

Hebrew University of Jerusalem - Faculty of Dental Medicine

\section{Marcio Guelmann}

University of Florida

\section{Nili Tickotsky}

Bar Ilan University Mina and Everard Goodman Faculty of Life Sciences

\section{Rinat Ninio-Harush}

Hebrew University of Jerusalem - Faculty of Dental Medicine

\section{Avia Fux Noy}

Hebrew University of Jerusalem - Faculty of Dental Medicine

\section{Elinor Halperson}

Hebrew University of Jerusalem - Faculty of Dental Medicine

\section{Diana Ram}

Hebrew University of Jerusalem - Faculty of Dental Medicine

Moti Moskovitz ( $\nabla$ motim@md.huji.ac.il)

Hebrew University of Jerusalem - Faculty of Dental Medicine https://orcid.org/0000-0003-4118-2501

\section{Research article}

Keywords: Gas tension, Acidity levels, Biomarkers of pulp inflammation, Primary dentition

Posted Date: October 3rd, 2019

DOl: https://doi.org/10.21203/rs.2.15534/v1

License: (c) (1) This work is licensed under a Creative Commons Attribution 4.0 International License.

Read Full License 


\section{Abstract}

Background The purpose of this study was to determine if gas tension and acidity levels could serve as biomarkers of pulp inflammatory status in the primary dentition.

Methods The present study evaluated acidity level and blood partial pressures of 02 and CO 2 collected from vital pulp chambers of 84 primary molars with deep carious lesions encroaching the pulp. Teeth were treated with pulpotomy or pulpectomy based on clinical judgement after excision of the coronal pulp tissue. Pulpectomy was performed when positive history of symptoms, difficulty in obtaining hemostasis and/or dark purple blood were present. Using a glass capillary, pulp chamber bleeding was collected and within ten minutes a neonate Astrup test was performed to determine blood gas module $\mathrm{pH}$, pCO 2 , and pO 2 .

Results Eighty-four children with one affected tooth participated in the study (37 girls and 47 boys). Age ranged between 3.5 to 11 -years (average: 5.3 years). Seventy-one (84\%) were treated with the aid of inhalation analgesia, conscious sedation or general anesthesia. Pulpotomy was performed on 51 teeth $(61 \%)$. Teeth undergoing pulpectomy revealed significant higher level of $\mathrm{CO} 2$ partial pressure $(P<0.05)$ and acidity level values $(\mathrm{pH})$ were also lower in teeth with pulpectomy $(\mathrm{P}>0.05)$.

Conclusions Higher pCO 2 levels and lower pH were found in pulps needing pulpectomy.

\section{Background}

Vital pulp therapy in primary teeth is indicated for extensive tooth decay approximating the pulp of asymptomatic teeth or teeth with signs of reversible pulpitis [1]. Pre-operative diagnostic methods of pulp status in primary teeth are primarily based on clinical signs and symptoms, pain history and radiographic assessment [2-4].

After carious pulp exposure in vital primary teeth, treatment options are pulpotomy [5,6] or pulpectomy [1]. The success of vital pulp therapy strongly depends on the inflammatory status of the coronal and radicular pulp tissues [7]. While for healthy pulp tissue with inflammation confined to the coronal pulp, the recommended treatment is pulpotomy, for irreversible pulpitis the recommended treatment is pulpectomy [8]. Clinicians face the diagnostic difficulty of accurately assessing the inflammatory state of the pulp [3], a diagnosis that will determine tooth prognosis [3]. Ricucci et al. [3] found that cases with normal pulp and reversible pulpitis had higher correlation between the clinical and histologic diagnosis of pulp conditions than cases of irreversible pulpitis ( $96.6 \%$ and $84.4 \%$, respectively). Endodontic diagnostics showed higher competence at identifying persons who were free of pulpitis than at identifying pulpitis-positive persons, with a danger of false-positive misclassifications [9].

In the dental pulp, being an environment of low compliance and limited access constricted by the surrounding hard tissues, inflammation may induce unrepairable cell damage. In the case of pulpitis, inflammation increases the damage created by the bacterial infection $[10,11]$. Hypoxia influences the 
inflamed tissue environment by regulating oxygen-dependent gene expression [12]. Current nextgeneration diagnostics designed to assess the inflammatory state of the pulp at chairside, use blood or another tissue fluid to find quantitative biomarkers of disease [13,14] such as TGF- $\beta$ [15], Nitric oxide synthase [16] and histological composition of inflammatory cells in the inflamed pulp [17]. So far, many inflammation-related factors have been identified $[18,19]$ but no reliable, plain biomarkers that clearly distinguish pulpitis from reversible inflammation have been found [4].

Operative diagnosis currently relies on the color of exposed pulpal blood, bleeding duration and hemostasis achievement $[20,21]$, as these parameters do not necessitate any advanced technologies. Mutluay et al. evaluated bleeding control at the exposure site and at orifice site of primary molars with caries exposures. They concluded that hemostasis at the orifice site is paramount for the success of pulpotomy procedures [21]. Aaminabadi et al. assessed the relationship between pulp blood color and the histological and hematological features of the pulp tissue during pulpotomy and pulpectomy in primary molars. They found blood color significantly darker in the pulpectomy group and attributed it to the existence of more inflammation, stasis of blood in pulp tissue, decrease of $\mathrm{pH}$, increase of temperature, and poorly oxygenated hemoglobin [20]. The problem with blood color is that it is challenging to quantify it and thus it cannot serve as a biomarker. In the present study we aimed to quantify some of the factors that influence blood color and check if they can serve as biomarkers. Respiratory measurements such as oxygen probe and $\mathrm{CO}_{2}$ release techniques have been suggested to yield more sensitive indicators of pulp tissue injury than previously used histological techniques [22]. We examined whether the following three quantifiable parameters can serve to distinguish pulpitis from reversible inflammation: $\mathrm{pH}$ changes and blood partial pressure of both $\mathrm{O}_{2}$ and $\mathrm{CO}_{2}$.

Blood is normally slightly basic, alkaline, with a pH range of 7.35 to 7.45 . The $\mathrm{pH}$ of the extra cellular fluid in normal conditions is 7.4. Acidosis has been reported in inflamed tissues, and ions changes at the site of inflammation may provoke alterations in blood acid-base status [23,24]. Dental pulp is exposed to changes in extracellular $\mathrm{pH}$ under exposure to caries-associated bacteria [25]. Acidic extracellular pH condition is associated with growth arrest or death of dental pulp stem cells [25]. Oxygen saturation levels are an effective indicator of pulp vitality in primary teeth [26,27] as hypoxia promotes inflammation [12] and vice versa, leukocytes decrease pulp tissue $\mathrm{O}_{2}$.

The present study evaluated the level of acidity and blood partial pressure of $\mathrm{O}_{2}$ and $\mathrm{CO}_{2}$ in samples drawn from pulp chambers of primary molars undergoing pulpotomy or pulpectomy. We hypothesized that these parameters may differ significantly between the two states of pulp status. If confirmed, acidity level and blood partial pressure of $\mathrm{O}_{2}$ and $\mathrm{CO}_{2}$ in the pulp may potentially serve as biomarkers of the pulp inflammatory status helping clinicians select between performing pulpotomy or pulpectomy, improving tooth prognosis.

\section{Methods}

\section{Study Population}


Healthy children, three to eleven years old undergoing scheduled dental treatment at the Department of Pediatric Dentistry, with primary molars with deep carious lesions, absence of signs and symptoms of irreversible pulpitis were recruited for the study. Primary molars with advanced pulp degeneration or necrosis (e.g., suppuration, purulence) or radiographic signs of root resorption or periapical lesion were excluded from the study.

\section{Ethical considerations}

Study protocol was approved by the Institutional Human Subjects Ethics Committee of Hadassah Medical Organization, Jerusalem, Israel. All procedures performed were in accordance with the ethical standards of the Institution and National Research Committees with no compensation offered. A detailed information fact sheet in simple, non-technical language, was provided in advance. Parents/guardians of all patients included in the study were requested to sign an informed consent. The study protocol can be accessed at clinicaltrials.gov (NCT01486537).

\section{Samples collection}

After a local anesthetic with 2\% Xylocaine Dental with epinephrine 1:100,000 (lidocaine $\mathrm{HCl}$ and epinephrine Injection, USP. DENTSPLY Pharmaceutical, USA) and rubber dam isolation, cavity preparation was performed with a high-speed 330 SSW diamond bur (SS White ${ }^{\circledR}$ Burs, Inc. USA) under an air-water coolant. Dental caries was removed using low-speed, round steel burs (Emil Lange, Engelskirchen, Germany) prior to accessing the pulp chamber. After carious pulp exposure, pulp chamber was unroofed with a \#330 bur, and coronal pulp tissue excised up to the orifices of the pulp canals using a sterile, low speed round bur to avoid stretching of the pulps. At this phase, blood was collected by the operator using a sterile 100 microliter syringe pretreated with heparin solution (Heparin Injection BP 5,000 UNITS/ML, Rotexmedica, Trittau, Germany)-figure 1a. The operative decision of performing a pulpotomy or pulpectomy was based on bleeding color and whether hemostasis was obtained within 5 minutes with a cotton pellet placed inside the pulp chamber with light pressure. When positive history of symptoms, difficulty in obtaining hemostasis and/or presence of dark purple blood was present, pulpectomy was performed. Clinical and radiographic findings, and behavior guidance techniques utilized during treatment were documented.

Within ten minutes from collecting the pulpal blood sample, a neonate Astrup was performed using a glass capillary at the pediatric intensive care unit of the Medical Center (storage not needed). The Astrup method for determination of arterial $\mathrm{pH}, \mathrm{pCO}_{2}$, and "base excess" provides a simple and accurate means for quantitation of acid-base disorders. This method for determination of blood gas module $\mathrm{pH}, \mathrm{pCO}_{2}$, and $\mathrm{pO}_{2}$ was performed using cobas b $221 \mathrm{POC}$ system (Roche Diagnostics Ltd. CH-6343 Rotkreuz Switzerland), figure $1 \mathrm{~b}$. 


\section{Statistics}

Student's t-test and the non-parametric Mann Whitney test were used for data analysis. The correlation between each two quantitative parameters (e.g. age and $\mathrm{pH}, \mathrm{pCO}_{2}, \mathrm{pO}_{2}$ ) was estimated by calculating Pearson correlation coefficient. The comparison of $\mathrm{pO}_{2}$ and $\mathrm{pCO}_{2}$ values in pulpotomized teeth to $\mathrm{pO}_{2}$ and $\mathrm{pCO}_{2}$ values in pulpectomized teeth was performed using One-sample t-test. The software used for statistical analysis was IBM ${ }^{\circledR}$ SPSS ${ }^{\circledR}$ Statistics version 20 for Windows and level of significance set at $\mathrm{p}<0.05$. Results presented as the mean \pm standard error.

\section{Results}

Eighty-four children participated in the study (37 girls and 47 boys). Age ranged between 3.5 to 11-years (average: 5.3 year). Seventy-one children (84\%) were treated with the aid of inhalation analgesia (nitrous oxide), conscious sedation (oral midazolam, hydroxyzine or a combination of the two) and general anesthesia. Twenty-two teeth were first primary molars and 62 teeth were second primary molars. Pulpotomy was performed on 51 teeth (61\%).

\section{Acidity level:}

Pulpotomy samples had a tendency toward a more basic $\mathrm{pH}$ compared to the pulpectomy samples. The average $\mathrm{pH}$ for teeth treated with pulpotomy was 7.535 while 7.508 for pulpectomy $(P>0.05)$, figure $2 a$.

\section{Gas tension:}

The average $\mathrm{pO}_{2}$ for teeth treated with pulpotomy was $175.6 \mathrm{mmHg}$, while the average $\mathrm{pO}_{2}$ for pulpectomy was $178 \mathrm{mmHg}(\mathrm{P}>0.05)$, figure $2 \mathrm{~b}$. The average $\mathrm{pCO}_{2}$ for teeth treated with pulpotomy was $9.4 \mathrm{mmHg}$ while in the pulpectomy group the average $\mathrm{pCO}_{2}$ was $13.4 \mathrm{mmHg}(P<0.05)$, figure 2c.

\section{Behavior guidance:}

Twelve children were treated using local anesthesia alone, 62 children under nitrous oxide and conscious sedation and 10 were treated under general anesthesia. None of the behavior guidance techniques influenced the $\mathrm{pH}(\mathrm{p}=0.630)\left(\mathrm{pO}_{2}(\mathrm{p}=0.481)\right.$ and $\left.\mathrm{pCO}_{2}(\mathrm{p}=0.150)\right)$.

\section{Type of tooth:}

Twelve teeth were first primary molars and 62 second primary molars. Type of treated tooth had a significant effect on blood samples $\mathrm{pH}(\mathrm{p}=0.005)$, but not on the $\mathrm{pO}_{2}(\mathrm{p}=0.260)$ or $\mathrm{pCO}_{2}(\mathrm{p}=0.146)$. 


\section{Discussion}

In an effort to find parameters that differ significantly between reversibly and irreversibly damaged pulp, we measured acidity level and blood partial pressure of $\mathrm{O}_{2}$ and $\mathrm{CO}_{2}$ of the pulp in primary molars that underwent either pulpotomy or pulpectomy treatment.

The $\mathrm{pH}$ of normal human dental pulp tissue is $7.4 \pm 0.2$ [28]. We hypothesized that the $\mathrm{pH}$ of an inflamed pulp will be more acidic than that of a healthy pulp, since low extracellular $\mathrm{pH}$ (i.e., tissue acidosis) is frequently seen in inflamed tissue [12], but our results showed that inflamed tissue $\mathrm{pH}$ is slightly more alkalosis than in healthy pulp. Although this finding was statistically non-significant, it is interesting to note that the pulp's tendency towards alkalosis is a part of its regeneration process, as increased intracellular $\mathrm{pH}$ serves as a permissive or obligatory signal for cell proliferation [25]. Okabe et al. have shown that human dental pulp cell mineralization is enhanced in alkaline $\mathrm{pH}$ conditions: both alkaline phosphatase (ALP) activity and quantity of bone morphogenetic protein 2 (BMP-2) were increased at pH 7.8 compared with cells cultured in pH 7.2 conditioned medium [29]. BMP-2 accelerates the differentiation of human dental pulp cells into odontoblasts and increases the activity ALP [30], a known indicator of osteoblast differentiation and osteogenesis [29].

The highly constricted anatomy of the dental pulp leads to high capillary pressures [31]. Normal pulpal capillary pressure is relatively high ( $35 \pm 0.8 \mathrm{mmHg}$ ) [32], and pulpal interstitial fluid pressure (IFP), in contrast to most other tissues, is well above atmospheric pressure $(6-60 \mathrm{mmHg})$ [2]. During inflammation, the IFP of dental pulp increases approximately threefold [2].

The values of gases partial pressures in our study are higher than values found in blood capillaries, where $\mathrm{pCO}_{2}$ is $35.00 \otimes 45.00 \mathrm{mmHg}$ and $\mathrm{pO}_{2}$ is $75.00 \otimes 100.00 \mathrm{mmHg}[26,33,34]$. The literature lacks agreement between results on tissues $\mathrm{pO}_{2}$ distribution [35]. Differences are introduced by the method for exposing the tissue, the variability between tissue, differences in measurement methods and the intrinsic potential variability due to the location of the measurement site along the microvasculature [35]. Therefore, we compared the values measured between the two groups of teeth and more studies are needed to provide further data on pulp gases partial pressures.

Significantly higher $\mathrm{pCO}_{2}$ values were found in teeth scheduled for pulpectomy. High carbon dioxide pressure is a result of inflammatory environment. $\mathrm{CO}_{2}$ can combine reversibly with $\mathrm{H}_{2} \mathrm{O}$ to yield a strongly acidic $\mathrm{H}+$ ion and a weak basic bicarbonate ion $\left(\mathrm{HCO}_{3}-\right) \cdot \mathrm{CO}_{2} / \mathrm{HCO}_{3}$ serves to buffer the system and induce $\mathrm{pH}$ recovery after induced-intracellular alkalosis [30]. We assume that in severely inflamed pulps the extracellular high levels of $\mathrm{CO}_{2}$ serves to cope with the inflammatory state and may contribute to the pulp's $\mathrm{pH}$ tendency towards alkalosis.

The slightly higher $\mathrm{pO}_{2}$ measured in samples from teeth that underwent pulpectomy in comparison to those treated with pulpotomy may be explained by the fact that tissues in a state of acute inflammation 
present vasodilation and increased vascular permeability that allows leukocytes entrance into the pulp tissue $[10,18]$.

Our results showed that, in inflamed pulp tissue, the partial $\mathrm{CO}_{2}$ pressure is higher than in healthy pulp tissue, $\mathrm{pH}$ is slightly more alkalosis and partial $\mathrm{O}_{2}$ pressure is slightly higher. These small differences between reversibly and irreversibly damaged pulp tissues demonstrate the proximity of the two conditions. The present study is a step towards finding further measures that will shed light on the fine transition from reversible inflammation state to irreversibly damaged pulp tissue.

\section{Conclusions}

The following conclusions were drawn from the study:

1. Significantly higher $\mathrm{pCO}_{2}$ levels were found in pulps needing pulpectomy;

2. More acidic $\mathrm{pH}$ could be found in pulps needing pulpectomy.

\section{Declarations}

- Ethics approval and consent to participate

Study protocol was approved by the Institutional Human Subjects Ethics Committee of Medical Organization IRB (0401-11-HMO).

All procedures performed in studies involving human participants were in accordance with the ethical standards of the institutional and/or national research committee and with the 1964 Helsinki declaration and its later amendments or comparable ethical standards.

Informed consent was obtained from all parents or caregiver of the participants included in the study.

- Consent for publication

Not applicable

- Availability of data and materials

Data sharing is not applicable to this article as no datasets were generated or analyzed during the current study.

- Competing interests 
The authors declare that they have no competing interests

- Funding

No Funding

- Authors' contributions

AS, MG, NT and MM contributed to the design of the study. AS, RNH, AFN, EH, DR, participated in obtaining and analyzing blood samples. AS, MG, NT and MM interpreted the patient data and were major contributors in writing the manuscript. All authors read and approved the final manuscript

- Acknowledgements

Not applicable

\section{References}

1. Smaïl-Faugeron V, Courson F, Durieux P, Muller-Bolla M, Glenny AM, Fron Chabouis H. Pulp treatment for extensive decay in primary teeth. Cochrane Database Syst Rev. 2014;6( 8):CD003220. 2. Heyeraas KJ, Berggreen E. Interstitial fluid pressure in normal and inflamed pulp. Crit Rev Oral Biol Med.

1999;10(3):328-36. 3. Ricucci D, Loghin S, Siqueira JF Jr. Correlation between clinical and histologic pulp diagnoses. J Endod. 2014;40(12):1932-9. 4. Kearney M, Cooper PR, Smith AJ, Duncan HF. Epigenetic Approaches to the Treatment of Dental Pulp Inflammation and Repair: Opportunities and Obstacles. Front Genet. 2018;7;9:311. 5. Smaïl-Faugeron V, Glenny AM, Courson F, Durieux P, Muller-Bolla M, Fron Chabouis H. Pulp treatment for extensive decay in primary teeth. Cochrane Database Syst Rev.

2018;31;5:CD003220. 6. Dhar V, Marghalani AA, Crystal YO, Kumar A, Ritwik P, Tulunoglu O, Graham L. Use of Vital Pulp Therapies in Primary Teeth with Deep Caries Lesions. Pediatr Dent. 2017 15;39(5):14659. 7. Waterhouse PJ, Nunn JH, Whitworth JM, Soames JV. Primary molar pulp therapy-histological evaluation of failure. Int J Paediatr Dent. 2000;10(4):313-21. 8. Pulp Therapy for Primary and Immature Permanent Teeth. Pediatr Dent Reference Manual V40/NO6 18/19 2018;343-351. 9. Hyman JJ, Cohen ME. The predictive value of endodontic diagnostic tests. Oral Surg Oral Med Oral Pathol. 1984;58(3):3436. 10. Maltos KL, Menezes GB, Caliari MV, Rocha OA, Santos JM, Alves DL, Duarte ID, Francischi JN. Vascular and cellular responses to pro-inflammatory stimuli in rat dental pulp. Arch Oral Biol. 2004;49(6):443-50. 11. Martin FE. Carious pulpitis: microbiological and histopathological considerations. Aust Endod J. 2003;29(3):134-7. 12. Eltzschig HK, Carmeliet P. Hypoxia and inflammation. N Engl J Med. 2011;364(7):656-65. 13. da Rosa WLO, Piva E, da Silva AF. Disclosing the physiology of pulp tissue for vital pulp therapy. Int Endod J. 2018;51(8):829-46. 14. Mente J, Petrovic J, Gehrig H, Rampf S, Michel A, Schürz A, Pfefferle T, Saure D, Erber R. A Prospective Clinical Pilot Study on the Level of Matrix Metalloproteinase-9 in Dental Pulpal Blood as a Marker for the State of Inflammation in the Pulp Tissue. J Endod. 2016;42(2):190-7. 15. Piattelli A, Rubini C, Fioroni M, Tripodi D, Strocchi R. Transforming growth factor-beta 1 (TGF-beta 1) expression in normal healthy pulps and in those with irreversible pulpitis. Int 
Endod J. 2004;37(2):114-9. 16. Di Nardo Di Maio F, Lohinai Z, D'Arcangelo C, De Fazio PE, Speranza L, De Lutiis MA, Patruno A, Grilli A, Felaco M. Nitric oxide synthase in healthy and inflamed human dental pulp. J Dent Res. 2004;83(4):312-6. 17. Bruno KF, Silva JA, Silva TA, Batista AC, Alencar AH, Estrela C. Characterization of inflammatory cell infiltrate in human dental pulpitis. Int Endod J. 2010;43(11):101321. 18. Rechenberg DK, Galicia JC, Peters OA. Biological Markers for Pulpal Inflammation: A Systematic Review. PLoS One. 2016;11(11):e0167289. 19. Stella JP, Barletta FB, Giovanella LB, Grazziotin-Soares R, Tovo MF, Felippe WT, Estrela C. Oxygen Saturation in Dental Pulp of Permanent Teeth: Difference between Children/Adolescents and Adults. J Endod. 2015;41(9):1445-9. 20. Aaminabadi NA, Parto M, Emamverdizadeh P, Jamali Z, Shirazi S. Pulp bleeding color is an indicator of clinical and histohematologic status of primary teeth. Clin Oral Investig. 2017;21(5):1831-41. 21. Mutluay M, Arıkan V, Sarı S, Kısa Ü. Does Achievement of Hemostasis After Pulp Exposure Provide an Accurate Assessment of Pulp Inflammation? Pediatr Dent. 2018;40(1):37-42. 22. Biesterfeld RC, Taintor JF, Marsh CL. The significance of alterations of pulpal respiration. A review of literature. J Oral Pathol. 1979;8(3):129-39. 23. Alfaro V, Ródenas J, Palaclos L, Mitjavila MT, Carbonell T. Blood acid-base changes during acute experimental inflammation in rats. Can J Physiol Pharmacol. 1996;74(3):313-9. 24. Becker DE, Reed KL. Local anesthetics: review of pharmacological considerations. Anesth Prog. 2012;59(2):90-101. 25. Hirose Y, Yamaguchi M, Kawabata S, Murakami M, Nakashima M, Gotoh M, Yamamoto T. Effects of Extracellular pH on Dental Pulp Cells In Vitro. J Endod. 2016;42(5):735-41. 26. Anusha B, Madhusudhana K, Chinni SK, Paramesh Y. Assessment of Pulp Oxygen Saturation Levels by Pulse Oximetry for Pulpal Diseases -A Diagnostic Study. J Clin Diagn Res. 2017;11(9):ZC36-ZC39. 27. Shahi P, Sood PB, Sharma A, Madan M, Shahi N, Gandhi G. Comparative Study of Pulp Vitality in Primary and Young Permanent Molars in Human Children with Pulse Oximeter and Electric Pulp Tester. Int J Clin Pediatr Dent. 2015;8(2):94-8. 28. Chen GS, Lee SP, Huang SF, Chao SC, Chang CY, Wu GJ, Li CH, Loh SH. Functional and molecular characterization of transmembrane intracellular $\mathrm{pH}$ regulators in human dental pulp stem cells. Arch Oral Biol. 2018;90:19-26. 29. Okabe T, Sakamoto M, Takeuchi H, Matsushima K. Effects of pH on mineralization ability of human dental pulp cells. J Endod. 2006;32(3):198-201. 30. Saito T, Ogawa M, Hata Y, Bessho K. Acceleration effect of human recombinant bone morphogenetic protein-2 on differentiation of human pulp cells into odontoblasts. J Endod. 2004;30(4):205-8. 31. Donaldson LF. Understanding pulpitis. J Physiol. 2006;573(Pt 1):2-3. 32. Matthews B, Andrew D. Microvascular architecture and exchange in teeth. Microcirculation. 1995;2(4):305-13. 33. Freckmann G, Schmid C, Baumstark A, Pleus S, Link M, Haug C. Partial pressure of oxygen in capillary blood samples from the fingertip. J Diabetes Sci Technol. 2013;7(6):1648-9. 34. Setzer FC, Kataoka SH, Natrielli F, Gondim-Junior $\mathrm{E}$, Caldeira CL. Clinical diagnosis of pulp inflammation based on pulp oxygenation rates measured by pulse oximetry. J Endod. 2012;38(7):880-3. 35. Weiner M. Concepts of "tissue PO2" in relation to 02 delivery. Artif Cells Blood Substit Immobil Biotechnol. 1994;22(3):763-8.

\section{Figures}



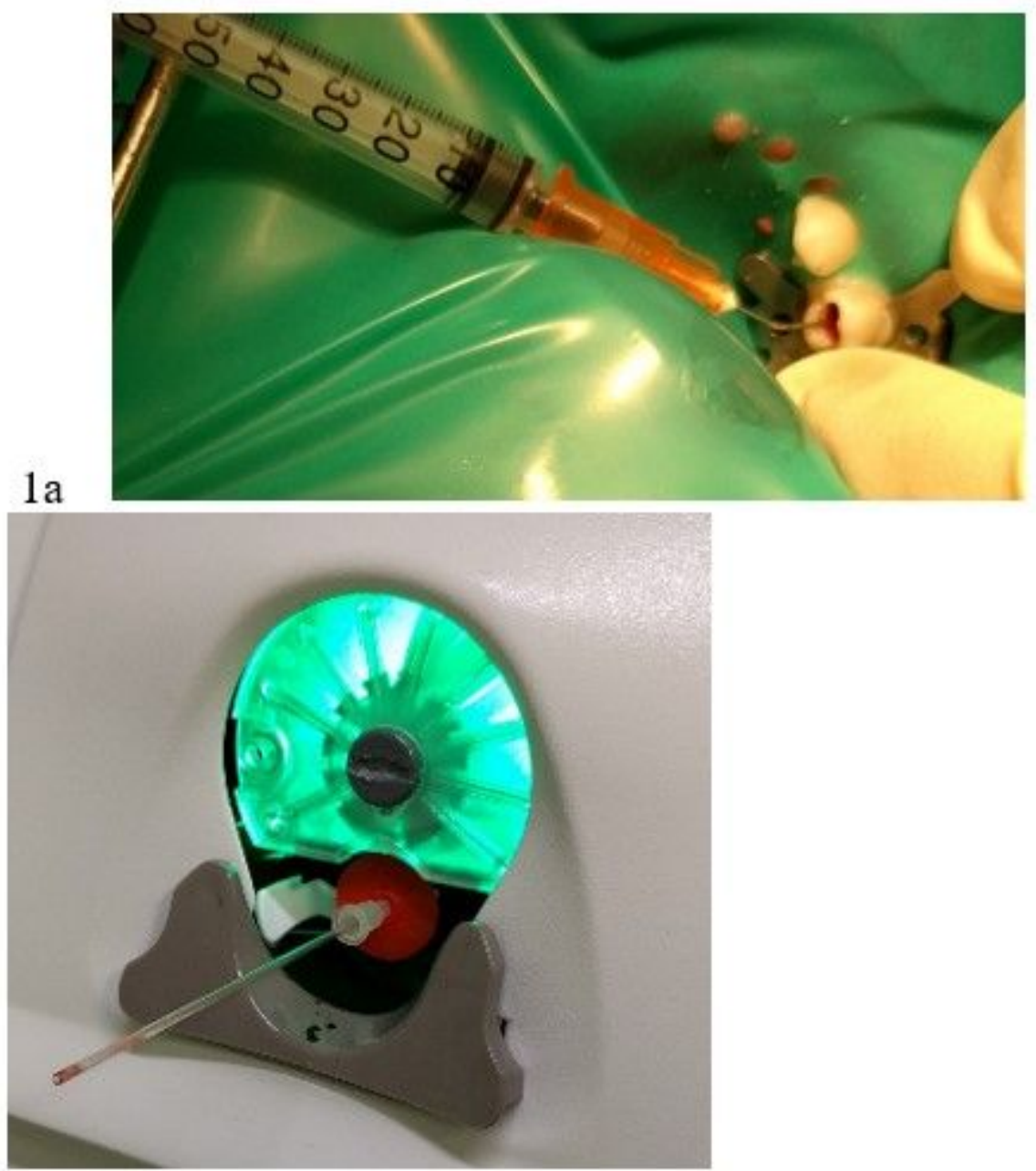

$1 \mathrm{~b}$

\section{Figure 1}

a. collecting blood using a sterile 100-microliter syringe pretreated with heparin and b. performing a neonate Astrup using a glass capillary this is a method for determination of blood gas module $\mathrm{pH}, \mathrm{pCO} 2$, and p02 using cobas b 221 POC system (Roche Diagnostics Ltd. CH-6343 Rotkreuz Switzerland), 


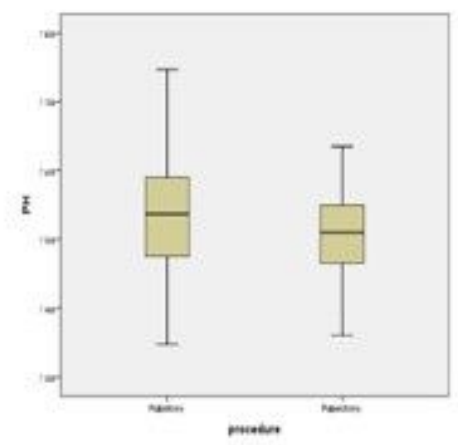

Figure 2b: $\mathrm{pO}_{2}$ levels in samples taken from pulpotomised vs. pulpectomised teeth

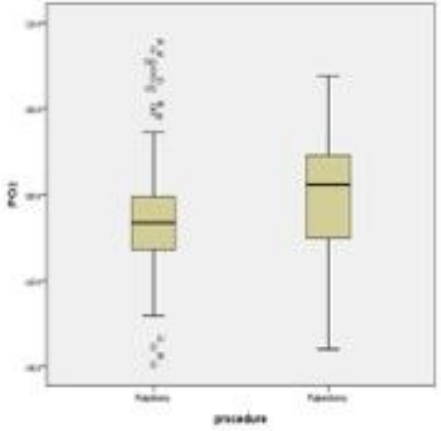

Figure 2c: $\mathrm{pCO}_{2}$ levels in samples tziken from pulpotomised vs. pulpectomised teeth

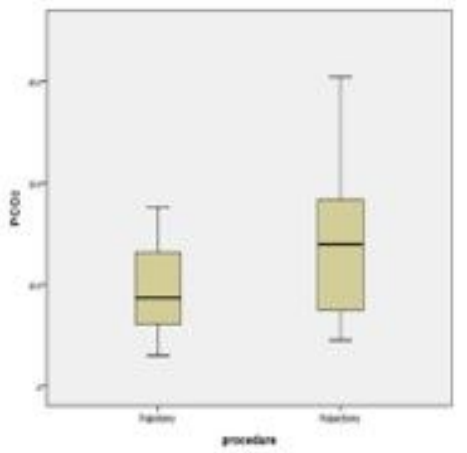

\section{Figure 2}

Figure 2a: $\mathrm{pH}$ levels of samples taken from pulpotomised vs. pulpectomised teeth Figure $2 \mathrm{~b}$ : $\mathrm{p0} 2$ levels in samples taken from pulpotomised vs. pulpectomised teeth Figure 2c: pCO2 levels in samples taken from pulpotomised vs. pulpectomised teeth 